\title{
Systemic Functional Linguistics as a model for text analysis
}

David Banks

\section{(2) OpenEdition}

1 Journals

\section{Electronic version}

URL: http://journals.openedition.org/asp/1584

DOI: 10.4000/asp.1584

ISBN: 978-2-8218-0388-6

ISSN: 2108-6354

\section{Publisher}

Groupe d'étude et de recherche en anglais de spécialité

\section{Printed version}

Date of publication: 1 December 2002

Number of pages: 23-34

ISSN: 1246-8185

\section{Electronic reference}

David Banks, « Systemic Functional Linguistics as a model for text analysis », ASp [Online], 35-36 |

2002, Online since 05 August 2010, connection on 21 December 2020. URL : http://

journals.openedition.org/asp/1584; DOI : https://doi.org/10.4000/asp.1584

This text was automatically generated on 21 December 2020.

Tous droits réservés 


\title{
Systemic Functional Linguistics as a model for text analysis
}

\author{
David Banks
}

\section{Objective}

1 In this article I hope to show that Systemic Functional Linguistics (henceforth SFL) ${ }^{1}$ is a useful and indeed powerful tool for the analysis of text. I would like to state at the outset that this is not intended to be to the exclusion of other types of approach, which may well be useful and powerful in their own right, and in perhaps different ways. However the scope of this article will be limited to discussion of SFL, and hence will not take comparative considerations into account. In view of this, the article will be more in the nature of a demonstration than a research article proper. I shall present a mini-corpus which will be analysed for the needs of the demonstration, and I will outline the register ${ }^{2}$ and semantics strata of the SFL model. I will comment on a partial analysis of the two texts, and discuss differences between the two texts which are brought out by the analyses.

\section{Mini-corpus}

2 For the needs of my demonstration, I will consider a mini-corpus of two short texts. These are reproduced in Appendix 1. The object of having short texts is that this enables us to deal with the texts as a whole within the scope of the article, rather than simply extracts, or selected aspects. Both texts are abstracts to research articles and both were published in 1996. The first concerns particle physics and consists of eight finite clauses totalling 106 words, an average of 13.25 words per clause. The second is from the area of ESP, and consists of nine finite clauses totalling 134 words, an average of 14.89 words per clause. Particle physics is a domain with which I have no familiarity, and I suspect this is the case for the majority of readers of ASp; on the other hand, ESP is an area which I, and I 
presume most readers are (perhaps some will say "all too") familiar. I have not sought specialist help on the physics text since I believe it is interesting to see to what extent the language of a text can be understood by the linguist even in a field with which he is unfamiliar.

\section{Register}

SFL deals with register in terms of three variables or parameters known as semiotic functions. These are Field, Tenor and Mode ${ }^{3}$ (Halliday 1978). Field is the area of external reality with which the text deals. Tenor concerns the relationships between those taking part in the linguistic act. Mode is the means through which the communication takes place.

In terms of our corpus, the two texts are virtually the same in terms of Tenor and Mode, though they differ somewhat in Field. For both, Field is the domain of academic research, but there are some differences due to their being from different disciplines: the physics article deals with ions and ion collisions, while the ESP text is a linguistic analysis of medical texts, and more precisely of lexical verbs in those texts.

The Tenor establishes the communication as being between a researcher, or in the case of the physics article, a group of researchers since there are 4 co-authors, and other researchers in that discipline. This situation is however complicated by the fact that the channels of communication have gatekeepers in the form of editors and referees. The writers have to convince and satisfy these gatekeepers before they can communicate with their ultimate addressees, other researchers in their discipline to whom they wish to communicate the results of their research (Swales 1990; Sionis 1995, 1997; Kourilová 1996).

Mode is usually conceived of in terms of written or spoken communication. In the case of these two texts the Mode is written to be read silently, though it could be noted that these texts are components in a text complex, and the reading of this complex is probably rarely linear. Reading of the abstract almost certainly follows the title, and for many readers may well follow reading of the bibliography, or at least reference to it, for this itself is probably not read in linear fashion. For some readers, reading of the abstract may follow the conclusion, and perhaps in some cases, particularly if the reader is familiar with an author and his work, the abstract may be by-passed altogether.

\section{Semantic Metafunctions}

The semantic component of the SFL model is construed in terms of three metafunctions, ideational, interpersonal and textual. The ideational metafunction is that part of the meaning which concerns the way external reality is represented in the text. In informal terms it might be thought of as the content of the message, and is probably what many think of first when they refer to a semantic component. This means that it is intimately concerned with the processes involved, whether they be actions, events or states, the entities involved in these processes, and if mentioned the circumstances within which they take place. The interpersonal metafunction concerns the relationships that exist between the speaker and his addressee(s), and between the speaker and his message. The textual metafunction is that part of the meaning potential which makes a text into a text, 
as opposed to a simple string of words or clauses. It thus involves phenomena such as thematic structure, information structure, and cohesion.

It will be evident that there is a close connection between the three semiotic functions and the three semantic metafunctions. Indeed they dovetail into one another:

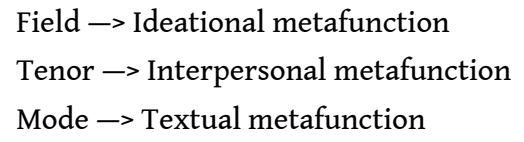

Just as the encoding in language depends on the semantic metafunctions, so the content of the metafunctions themselves depends on and is determined by the semiotic functions of register. Hence the insistence within SFL on the importance of the connection between context and language. Language cannot be divorced from the context which produces it.

A major component of the ideational metafunction is transitivity. In SFL transitivity is much more than the traditional distinction between transitive and intransitive verbs; it is concerned with the type of process involved in a clause, the participants implicated in it, and, if there are any, the attendant circumstances. Transitivity is thus the relationships established between the processes, the participants and the circumstances encoded in the clause. A major feature of the interpersonal metafunction is that of mood. Mood is analysed in terms of a Mood element and the Residue. The Mood element is constituted by the Subject and the Finite. The Finite, which to the best of my knowledge is not specifically defined or isolated in any other theory, is that element which, with the Subject, enables us to determine the mood of a clause. In English the Finite is encoded in the first (the leftmost) auxiliary in the verbal group. Hence, the order Subject ${ }^{\wedge}$ Finite establishes the mood as declarative, while the order Finite ${ }^{\wedge}$ Subject establishes the mood as interrogative. ${ }^{4}$

One of the major elements of the textual metafunction is that of thematic structure, which is an analysis of the clause in terms of Theme, the speaker's starting point and Rheme, where the clause goes from there.

In what follows I shall provide an analysis of transitivity, mood, and thematic structure. However, it should be noted that this does not exhaust the possibilities of the three metafunctions. For example, transitivity could be paralleled by an analysis of the ergative structure in terms of Agent, Process and Medium (Halliday 1994; Thompson 1996). Modality, in all its forms, constitutes a significant element of the interpersonal metafunction. And the textual metafunction in addition to thematic structure, includes, for example, information structure (analysed in terms of Given and New or, as I prefer to say, Focalized, the problem with the term New being that many examples of New are not at all new in the ordinary sense of the word; hence as a technical term, New is opaque and confusing for students), and cohesion.

\section{Analyses}

I shall now comment in detail on the analysis of the first four clauses of each text. The complete analysis of the physics text can be found in Appendix 2, and that of the ESP text in Appendix 3. The clauses of the physics abstract are numbered P1, P2, P3, etc., those of the ESP abstract, L1, L2, L3, etc. 
Clause 1 Physics abstract (P1)

\begin{tabular}{|c|c|c|c|c|}
\hline Slow ... ions & \multicolumn{2}{|c|}{ are scattered } & from ... surfaces & under ... incidence \\
\hline Affected & \multicolumn{2}{|l|}{ Pro: mat } & Circ: place & Circ: instr \\
\hline \multicolumn{2}{|l|}{ Mood } & \multicolumn{3}{|l|}{ Residue } \\
\hline Th: top & Rheme & & & \\
\hline
\end{tabular}

Slow $\mathrm{N}^{+}, \mathrm{N}^{2+}$ and $\mathrm{N}^{2} 0^{+}$ions are scattered from partially caesiated $\mathrm{W}(110)$ surfaces under grazing incidence.

The transitivity analysis of P1 shows that in this clause we have a verbal group encoding a process, are scattered, which takes place in a physical environment, and hence is a Material Process. This verbal group is in the passive voice and so it is fairly natural to find the Affected, Slow $\mathrm{N}^{+}, \mathrm{N}^{2}$ and $\mathrm{N}^{2} \mathrm{O}^{+}$, in subject position. This is accompanied by two circumstantial adjuncts, one of place, from partially caesiated $W(110)$ surfaces, and one expressing instrumental involvement, under grazing incidence. The Mood element is made up of the subject group and the Finite, are, the remainder of the clause being the Residue. In thematic structure, major components of the clause (Subject, Predicator, Complement or circumstantial Adjunct) constitute topical themes when in thematic position. In this case the Subject is the topical Theme, the rest of the clause is the Rheme.

Clause 2 Physics abstract (P2)

\begin{tabular}{|l|l|}
\hline The collision ... processes) & $\begin{array}{l}\text { is } \\
\text { studied }\end{array}$ \\
\hline Phenomenon & \multicolumn{1}{l|}{$\begin{array}{l}\text { Pro: } \\
\text { ment }\end{array}$} \\
\hline Mood & Residue \\
\hline Th: top & Rheme \\
\hline
\end{tabular}

The collision-induced emission of electrons (due to inter- and intra-atomic Auger processes) is studied.

In $\mathrm{P} 2$, the verbal group indicates an event which takes place essentially in the cerebral domain and is hence a Mental Process. The verbal group is again in the passive voice and hence it is usual to find, as here, the content of the mental process, the Phenomenon, The collision-induced emission of electrons (due to inter-and intra-atomic Auger processes), in subject position. The Mood is the Subject plus the Finite, is, with studied as the Residue. The Subject is the topical Theme, and the rest of the clause, is studied, functions as Rheme.

Clause 3 Physics abstract (P3)

\begin{tabular}{|l|l|l|}
\hline We & provide & evidence that ... process \\
\hline
\end{tabular}




\begin{tabular}{|c|c|c|c|}
\hline Sayer & Pro: verb & & Verbiage \\
\hline \multicolumn{2}{|l|}{ Mood } & \multicolumn{2}{|l|}{ Residue } \\
\hline Th: top & Rheme & & \\
\hline
\end{tabular}

We provide evidence that the metastable negative nitrogen ion state $\mathrm{N}^{*}\left({ }^{1} \mathrm{D}\right)$ is formed in a two-step capture process.

In $\mathrm{P}$, the verbal group is provide, but this provision is not a physical matter, but a question of communication, and hence is analysed as Verbal Process. The instigator of this verbal process, We, is the Sayer; and the content of the communication, evidence that the metastable negative nitrogen ion state $N^{*}\left({ }^{1} D\right)$ is formed in a two-step capture process, is the Verbiage (as a technical term this word has no derogatory overtones). The verbal group of this clause has no auxiliaries, and in this case SFL posits that the Finite is fused with the lexical verb. Hence the Mood is made up of the Subject and the fused Finite which is in the verb. The remainder of the clause constitutes the Residue. Once again it is the Subject which constitutes the topical Theme, the rest of the clause being the Rheme. ${ }^{5}$

Clause 4 Physics abstract (P4)

\begin{tabular}{|c|c|c|c|c|}
\hline that & the $\ldots \mathrm{N}^{-*}\left({ }^{1} \mathrm{D}\right)$ & \multicolumn{2}{|l|}{ is formed } & in a $\ldots$ process \\
\hline & Result & \multicolumn{2}{|l|}{ Pro: mat } & Circ: manner \\
\hline & \multicolumn{2}{|l|}{ Mood } & \multicolumn{2}{|l|}{ Residue } \\
\hline Th: text & Th: top & \multicolumn{3}{|l|}{ Rheme } \\
\hline
\end{tabular}

that the metastable negative nitrogen ion state $\mathrm{N}^{-*}\left({ }^{1} \mathrm{D}\right)$ is formed in a two-step capture process.

17 P3 includes a rankshifted clause $\mathrm{P} 4$, that the metastable negative nitrogen ion state $\mathrm{N}^{* *}\left({ }^{1} \mathrm{D}\right)$ is formed in a two-step capture process, which functions as the qualifier of evidence in P3. P4 has a verbal group, is formed, which is a Material Process. Here, the Subject of this material process is a Result rather than an Affected, since it is created by the process. It is also accompanied by a circumstantial Adjunct of manner, in a two-step capture process. The Mood is once again the Subject plus Finite, with the remainder of the clause constituting the Residue. The totality of this clause forms part of the Rheme of P3. Nevertheless it is possible to consider the internal thematic structure of this rankshifted clause. In that case the conjunction, that, since it precedes the topical Theme forms part of the thematic material, and is a textual Theme; this is followed by the topical Theme, constituted by the Subject, the rest of the clause functioning as Rheme.

Clause 1 ESP abstract (L1)

\begin{tabular}{|l|l|l|}
\hline This paper & analyses & lexical verb use ... and experimental) \\
\hline Instrument & Pro: verb & Verbiage \\
\hline
\end{tabular}




\begin{tabular}{|l|l|l|}
\hline \multicolumn{2}{|l|}{ Mood } & Residue \\
\hline Th: top & Rheme \\
\hline
\end{tabular}

This paper analyses lexical verb use in two types of medical research articles (clinical and experimental).

In L1, the first clause of the ESP extract, the verb is analyses. The process here is however not about the process of analysing itself, but about the presentation of the analyses in the article; hence it is a question of communication and an example of Verbal Process. A Sayer is the initiator of an act of communication, and as such must be an animate entity, hence in this case, the Subject, This paper, cannot be a Sayer, except in some metaphorical sense; it is rather the means through which the unmentioned sayer, the researcher, carries out his act of communication. This paper is therefore analysed as Instrument. The segment lexical verb use in two types of medical research articles (clinical and experimental) expresses the content of the message and thus is the Verbiage. The Mood is constituted by the Subject and a fused Finite, the rest of the Clause being the Residue. The Subject is also the topical Theme, with the rest of the clause as Rheme.

Clause 2 ESP abstract (L2)

\begin{tabular}{|c|c|c|c|}
\hline The corpus & \multicolumn{2}{|c|}{ consists of } & two groups of four articles \\
\hline Carrier & \multicolumn{2}{|l|}{ Pro: rel } & Attribute \\
\hline \multicolumn{2}{|l|}{ Mood } & \multicolumn{2}{|l|}{ Residue } \\
\hline Th: top & Rheme & & \\
\hline
\end{tabular}

The corpus consists of two groups of four articles.

The verbal group of L2, consists of, is a Relational Process of the attributive type, with The corpus as Carrier and two groups of four articles as Attribute. Once again the Mood element is the Subject and a fused Finite, with the rest of the clause as Residue; and the Subject also functions as topical Theme with the rest of the clause as Rheme.

Clause 3 ESP abstract (L3)

\begin{tabular}{|l|l|}
\hline Finite ... words & $\begin{array}{l}\text { were } \\
\text { included }\end{array}$ \\
\hline Possessed & \multicolumn{2}{|l|}{ Pro: rel } \\
\hline Mood & \multicolumn{2}{l|}{ Residue } \\
\hline Th: top & Rheme \\
\hline
\end{tabular}

Finite and non-finite forms of verbs recurring at a frequency of over 4 per 10,000 words were included. 
The verbal group of L3, were included, also encodes a Relational Process. The notion of inclusion constitutes a metaphorical form of possession. However since the verb include can be passivized, it is possible, as here, to have only the Possessed expressed, in subject position. This Subject, Finite and non-finite forms of verbs occurring at a frequency of over 4 per 10,000 words, together with the Finite, were, constitute the Mood element, with what is left, included, as Residue. The Subject again functions as topical Theme, and the rest of the clause as Rheme.

Clause 4 ESP abstract (L4)

\begin{tabular}{|c|c|c|c|}
\hline Lists & \multicolumn{2}{|c|}{ were drawn up } & of verbs ... only \\
\hline Verb - & \multicolumn{2}{|l|}{ Pro: verb } & - iage \\
\hline \multicolumn{2}{|l|}{ Mood } & \multicolumn{2}{|l|}{ Residue } \\
\hline Th: top & Rheme & & \\
\hline
\end{tabular}

Lists were drawn up of verbs meeting this criterion in both groups and in one group only.

The verbal group of L4, were drawn up, is concerned with communication of data, and is therefore analysed as Verbal Process. The subject group is discontinuous, with of verbs meeting this criterion in both groups and in one group only, functioning as the qualifier of Lists. The whole of this therefore constitutes the Subject, and since it expresses the content of the message it is analysed as Verbiage in the transitivity analysis. The whole of this Subject together with the Finite, were, constitute the Mood element, leaving drawn up as the Residue. Since initial position is crucial to the status of Theme, only that part of the Subject in initial position, Lists, functions as Theme, with the rest of the clause as Rheme.

I would readily admit that not everything in these analyses is totally uncontroversial, but discussion of controversial points is beyond the scope of this article, which is intended to be a demonstration of the utility of SFL in text analysis, as was stated at the outset.

\section{Discussion}

I shall now attempt to compare the analyses of these two short texts. My comments are based on the full analyses to be found in Appendices 2 and 3.

Consideration of the analyses of mood structure might lead to the initial conclusion that there is little to say. It is true that the mood analysis shows that the Mood element is consistently Subject ${ }^{\wedge}$ Finite, indicating that all the clauses of these two texts are indicative declarative. This is what one would expect in this type of text, where interrogatives or imperatives would be highly unusual. However there are some minor details that might be noticed. The physics abstract uses only one fused finite in a verbal process; the ESP abstract uses 4, 2 verbal and 2 relational. Hence it is the physics text which makes more use of the resources of English, notably in the area of the system of voice. It might be hypothesized that the greater use of fused finites in the ESP article means that it is more notional and generic than the physics text. 
the former and 2 of the latter. Some commentators see a close connection between these two types, or even see verbal process as a sub-group of mental process (Berry 1975, Matthiessen 1995). Consideration of the verbal processes in the ESP text shows that 2 (out of 3) have an Instrument in subject position. The Sayer is not expressed in any of them. The physics text has only one verbal and one mental process. The clause with verbal process does have an expressed Sayer, and moreover this is encoded as the personal pronoun $W e$ in subject position. This seems to indicate that there is a degree of personalization in the physics abstract which is absent in the ESP abstract. The 3 examples of mental process ( 2 in the ESP text and one in the physics text) are all encoded in the passive voice, with the Phenomenon, which expresses the content of the message being communicated, in subject position.

The physics abstract has 7 circumstantial adjuncts. Three of the clauses have 2 each. The ESP abstract has 4 circumstantial adjuncts, with one clause having 2 . This seems to 
indicate that there is a greater tendency to make the circumstances explicit in the physics abstract. It will be noted that this is despite the fact that the average length of clauses is greater in the ESP abstract than in the physics abstract. An increased number of circumstantial adjuncts is frequently a cause of greater length, but that is not the case here. The longer length of the ESP clauses is to be found elsewhere, for example, in extensive qualifiers.

\section{Concluding remarks} texts. However, it must be stressed that it is not intended that these results be taken as typical of these sub-genres. The size of the corpus obviates that, and in any case that was not the object of the exercise. What has been said applies only to the two texts in question. At most, the results might be taken as providing provisional initial working hypotheses.

What I hope has been shown is that SFL provides an analytical framework which is interesting, useful and powerful for the analysis and comparison of texts. However, as I said at the outset, this is not to be understood as being to the exclusion of other possible theoretical approaches, which may well come to similar conclusions. But I would like to stress, particularly for readers who are less familiar with SFL, that this approach is not simply a technique of textual analysis, it is rather a total theory of language (cf. e.g. Halliday \& Matthiessen 1999), of which certain aspects lend themselves to the analysis of text. It may even be that some come to similar conclusions on an ad hoc or intuitive basis, but I always feel that intuitive findings need to be anchored in a theoretical framework in order to be of academic interest. Otherwise they remain at a fairly subjective level. As I hope has been shown here, the distinction in SFL of three levels (metafunctions) within the semantic component of the model helps highlight the features of the text in a particularly clear, powerful, and objective fashion.

\section{BIBLIOGRAPHY}

Berry, Margaret. 1975. Introduction to Systemic Linguistics, Vol 1, Structures and Systems. London: Batsford.

Bloor, Thomas \& Meriel Bloor. 1995. The Functional Analysis of English, a Hallidayan Approach. London: Arnold.

Eggins, Suzanne. 1994. An Introduction to Systemic Functional Linguistic. London: Pinter.

Halliday, M.A.K. 1978. Language as Social Semiotic, the social interpretation of language and meaning. London: Edward Arnold.

Halliday, M.A.K. 1994. An Introduction to Functional Grammar, 2nd. ed. London: Edward Arnold. 
Halliday, M.A.K. \& Christian Matthiessen. 1999. Construing Experience through Meaning, a languagebased approach to cognition. London: Cassel.

Kourilová, Magda. 1996. "Interactive functions of language in peer reviews of medical papers written by non-native users of English”. Unesco ALSED-LSP Newsletter 19/1, 4-21.

Lock, Graham. 1996. Functional English Grammar, An introduction for second language teachers. Cambridge: Cambridge University Press.

Matthiessen, Christian. 1995. Lexicogrammatical Cartography: English Systems. Tokyo: International Language Sciences Publishers.

Sionis, Claude. 1995. "Communication strategies in the writing of scientific research articles by non-native users of English". English for Specific Purposes 14/2, 99-113.

Sionis, Claude. 1997. "Stratégies et styles rédactionnels de l'article de recherché : les ressources de l'utilisateur nonnatif devant publier en anglais". ASp 15-18, 207-222.

Swales, John M. 1990. Genre Analysis. English in academic and research settings. Cambridge: Cambridge University Press.

Thompson, Geoff. 1996. Introducing Functional Grammar. London: Arnold.

\section{APPENDIXES}

\section{Appendix 1: Corpus texts}

Slow $\mathrm{N}^{+}, \mathrm{N}_{2}{ }^{+}, \mathrm{NO}^{+}$and $\mathrm{N}_{2} \mathrm{O}^{+}$ions are scattered from partially caesiated $\mathrm{W}(110)$ surfaces under grazing incidence. The collision-induced emission of electrons (due to inter- and intra-atomic Auger processes) is studied. We provide evidence that the metastable negative nitrogen ion state $\mathrm{N}^{* *}\left({ }^{1} \mathrm{D}\right)$ is formed in a two-step capture process: in the first step neutral nitrogen atoms are formed in excited multiplet states of the $\mathrm{N}_{2} \mathrm{P}_{3}$ configuration. In the second step an additional surface electron is attached to the excited parent neutral atoms. The excitation energy of $\mathrm{N}^{-*}\left({ }^{1} \mathrm{D}\right)$ with respect to the nitrogen ground state would be $1.4 \mathrm{eV}$; its lifetime must be shorter than $200 \mathrm{~ms}$.

Müller, H., D. Gador, F. Wieherhaus \& Kempter (1996): "Evidence for the formation of $\mathrm{N}^{* *}($ ${ }^{1}$ D) ions in ion-surface collisions", Journal of Physics B: Atomic, Molecular and Optical Physics, $29,715-723$.

This paper analyses lexical verb use in two types of medical research articles (clinical and experimental). The corpus consists of two groups of four articles. Finite and non-finite forms of verbs occurring at a frequency of over 4 per 10,000 words were included. Lists were drawn up of verbs meeting this criterion in both groups and in one group only. For the contextual study, verbs were classified into seven categories, reporting, observation, relations, defining, cause and effect (C\&E), change and growth (C\&G) and methods. Differences in the overall distribution by rhetorical section and in individual verb functions between the groups were assessed statistically. Analysis of the reporting function showed clinical reports to be more assertive while experimental studies were more tentative. Certain reporting verbs coincided with moves in the Discussion cycle in both series.

Williams, Ian A. (1996): “A Contextual Study of Lexical Verbs in Two Types of Medical Research Report: Clinical and Experimental”, English for Specific Purposes, 15:3, 175-197. 
Appendix 2: Analysis of physics abstract

$P_{1}$

\begin{tabular}{|c|c|c|c|c|}
\hline Slow ... ions & are & scattered & from ... surfaces & under ... incidence \\
\hline Affected & Pro: mat & & Circ: place & Circ: instr \\
\hline \multicolumn{2}{|l|}{ Mood } & Residue & & \\
\hline Th: top & Rheme & & & \\
\hline
\end{tabular}

$\mathrm{P}_{2}$

\begin{tabular}{|c|c|c|}
\hline The collision ... processes) & is & studied \\
\hline Phenomenon & \multicolumn{2}{|c|}{ Pro: ment } \\
\hline Mood & & Residue \\
\hline Th: top & \multicolumn{2}{|c|}{ Rheme } \\
\hline
\end{tabular}

$P_{3}$

\begin{tabular}{|l|l|l|}
\hline We & provide & evidence that ... process \\
\hline Sayer & Pro: verb & Verbiage \\
\hline Mood & \multicolumn{2}{|l|}{ Residue } \\
\cline { 2 - 2 } Th: Top & Rheme & \\
\hline
\end{tabular}

$\mathrm{P}_{4}$

\begin{tabular}{|c|c|c|c|c|}
\hline that & the .... $\mathrm{N}^{*}\left({ }^{\circ} \mathrm{D}\right)$ & is & formed & in a... process \\
\hline & Result & Pro: mat & & Circ: manner \\
\hline & Mood & & Residue & \\
\hline Th: text & Th: top & Rheme & & \\
\hline
\end{tabular}

$P_{5}$

\begin{tabular}{|l|l|l|l|}
\hline in the first step & neutral nitrogen atoms & are formed & in excited ... configuration \\
\hline Circ: time & Result & Pro: mat & Circ: manner \\
\hline Res - & Mood & - idue \\
\cline { 2 - 3 } & \multicolumn{3}{l}{} \\
\hline Th: top & Rheme \\
\hline
\end{tabular}

P6

\begin{tabular}{|c|c|c|c|c|}
\hline In the second step & an ... electron & is & attached & to the $\ldots$ atoms \\
\hline Circ: time & Affected & Pro: mat & & \begin{tabular}{|l} 
Circ: place \\
\end{tabular} \\
\hline Res - & Mood & & - idue & \\
\hline Th: top & Rheme & & & \\
\hline
\end{tabular}

P7

\begin{tabular}{|c|c|c|c|}
\hline The excitation .... state & would & be & $1.4 \mathrm{eV}$ \\
\hline Carrier & Pro: rel & & Attribute \\
\hline Mood & \multicolumn{3}{|c|}{ Residue } \\
\hline Th: top & Rheme & & \\
\hline
\end{tabular}

P8

\begin{tabular}{|l|l|l|}
\hline its lifetime & must be & shorter than $200 \mathrm{~ms}$ \\
\hline Carrier & Pro: rel & Attribute \\
\hline Mood & Residue \\
\hline Th: top & Rheme \\
\hline
\end{tabular}

\section{Appendix 3: Analysis of ESP abstract}


L1

\begin{tabular}{|l|l|l|}
\hline This paper & analyses & lexical verb use ... and experimental) \\
\hline Instrument & Pro:verb & Verbiage \\
\hline Mood & Residue \\
\hline Th: top & Rheme \\
\hline
\end{tabular}

$\mathrm{L}_{2}$

\begin{tabular}{|l|l|l|}
\hline The corpus & consists of & two groups of four articles \\
\hline Carrier & Pro: rel & Attribute \\
\hline Mood & Residue \\
\hline Th: top & Rheme \\
\hline
\end{tabular}

$\mathrm{L}_{3}$

\begin{tabular}{|l|l|l|}
\hline Finite .... words & \multicolumn{1}{|l|}{ were } & \multicolumn{1}{l|}{ included } \\
\hline Possessed & Pro: rel & \multicolumn{2}{|l|}{} \\
\hline Mood & Residue \\
\hline Th: top & Rheme \\
\hline
\end{tabular}

L4

\begin{tabular}{|c|c|c|c|}
\hline Lists & were & drawn up & of verbs ... only \\
\hline Verb - & Pro: verb & & - iage \\
\hline Mood & & Residue & \\
\hline Th: top & Rheme & & \\
\hline
\end{tabular}

Ls

\begin{tabular}{|c|c|c|c|c|}
\hline For the ...study & verbs & were & classified & into seven ... methods \\
\hline Circ: place & Phenomenon & Pro: ment & & Circ: manner \\
\hline Res - & Mood & & - idue & \\
\hline Th: Top & Rheme & & & \\
\hline
\end{tabular}

L6

\begin{tabular}{|l|l|l|l|}
\hline Differences .... between the groups & were & assessed & statistically \\
\hline Phenomenon & Pro: ment & Circ: manner \\
\hline Mood & Rheme & Residue & \\
\hline Th: top
\end{tabular}

L7

\begin{tabular}{|c|c|c|}
\hline Analysis ... function & showed & clinic reports ... tentative \\
\hline Instrument & \begin{tabular}{|l} 
Pro: verb \\
\end{tabular} & Verbiage \\
\hline Mood & \multicolumn{2}{|c|}{ Residue } \\
\hline
\end{tabular}

18

\begin{tabular}{|l|l|l|l|}
\hline while & experimental studies & were & more tentative \\
\hline \multirow{4}{*}{} & Carrier & Pro: rel & Attribute \\
\cline { 2 - 4 } & Mood & Residue \\
\hline Th: text & Th: top & Rheme \\
\hline
\end{tabular}

L9

\begin{tabular}{|l|l|l|l|}
\hline Certain reporting verbs & coincided with & moves ... cycle & in both series \\
\hline Possessed & Pro: rel & Possessor & Circ: place \\
\hline Mood & Residue \\
\hline Th: top & Rheme \\
\hline
\end{tabular}

\section{Appendix 4 Alternative thematic structure}

An anonymous ASp referee has suggested an alternative thematic structure analysis along the following lines:

\begin{tabular}{|l|l|l|l|}
\hline We & provide evidence & that the metastable ... state $\mathrm{N}^{*}\left({ }^{1} \mathrm{D}\right)$ & is formed ... process \\
\hline Th & $\mathrm{Rh}$ & Th & $\mathrm{Rh}$ \\
\hline Theme & Rheme \\
\hline
\end{tabular}


This deserves consideration. To what extent is an analysis of this type possible? There seem to be two conceivable cases: first, where a $\beta$-clause (i.e. subordinate, but not rankshifted) precedes an $\alpha$-clause (cf. e.g. Halliday 1994). This is obviously not the case in the present instance. The second possibility is where the first segment, We provide evidence (that), is interpreted as a grammatical metaphor of modality; in this case it is being read as an interpersonal disjunct. This is not totally unreasonable, but I do not believe it is the correct reading in this context. The scientists wish to attribute these results to their own experiment (the use of a personal pronoun in an abstract is in itself significant). The grammatical metaphor reading would remove this explicit attribution; I feel that the analysis which maintains it is more reasonable.

\section{NOTES}

1. For introductions to SFL see Eggins 1994, Bloor \& Bloor 1995, Lock 1996, Thompson 1996. These are all based on Halliday 1994. For more extensive treatments see Martin 1992, Matthiessen 1995, Halliday \& Matthiessen 1999. The Association Française de la Linguistique Systémique Fonctionnelle was created in July 2001. Their website can be found at <http://www.univ-brest.fr/ erla/aflsf/>. This includes a bilingual (English-French) list of SFL terminology.

2. In SFL the term register relates to the context of situation, the term genre being reserved for a higher stratum related to the context of culture. However, the area covered here by register would frequently be referred to as genre in many other approaches, and even some within SFL use genre in this sense.

3. It has become traditional in SFL to capitalize the initial letter of the names of functions.

4. The symbol ^ is to be read as "followed by", hence "Subject^ ${ }^{\wedge}$ Finite" means "Subject followed by Finite".

5. See Appendix 4 for an alternative thematic structure analysis.

\section{ABSTRACTS}

Although different theoretical models are complementary, functional models in general, and Systemic Functional Linguistics in particular lend themselves to the analysis of text. This is so at the level of register, in terms of Field, Tenor and Mode, as well as at the level of semantics in terms of ideational, interpersonal and textual metafunction. This paper will consider two abstracts for research articles, one from the area of particle physics, the other, ESP. These abstracts are very similar in terms of Field, Tenor and Mode, since the semiotics of research publishing functions in virtually the same way in these two disciplines. In terms of the semantic metafunctions, it is in the interpersonal metafunction that they differ least, as they function in the same way. Differences in the textual and ideational metafunctions seem to be more significant. My object here is not to claim that these two abstracts provide results which are typical for their sub-genres, but to demonstrate that Systemic Functional Linguistics provides a useful theoretical framework for the purposes of text analysis. 
Les différents modèles théoriques sont complémentaires ; néanmoins, les modèles fonctionnels en général et la Linguistique Systémique Fonctionnelle en particulier se prêtent à l'analyse des textes, tant au niveau du registre, en termes de Champ, Teneur et Mode, qu'au niveau de la sémantique, en termes de métafonctions idéationnelle, interpersonnelle et textuel. Cet article considère deux résumés d'articles de recherche, des domaines de la physique des particules et de l'anglais de spécialité. Du point de vue du Champ, de la Teneur et du Mode, ils se ressemblent, car la sémiotique de la publication de recherche fonctionne de façon quasi identique dans les deux disciplines. Du point de vue des métafonctions sémantiques, c'est au niveau de la métafonction interpersonelle que les textes diffèrent le moins car, d'une manière générale, ils fonctionnent de la même façon. Au niveau des métafonctions textuelles et idéationnelles en revanche, les différences semblent plus significatives. Mon objectif n'est pas de prétendre que les deux résumés peuvent être considérés comme typiques de leurs sous-genres, mais de montrer que la Linguistique Systémique Fonctionnelle constitue un cadre théorique intéressant pour l'analyse de texte.

\section{INDEX}

Mots-clés: analyse de texte, linguistique systémique fonctionnelle, LSF, métafonction sémantique, registre, résumé

Keywords: abstract, register, semantic metafunction, SFL, systemic functional linguistics, text analysis

\section{AUTHOR}

\section{DAVID BANKS}

